\title{
Conceitos sobre violência e dados socioeconômicos de pessoas em situação de pobreza extrema residentes em um município no Sul do Brasil
}

\section{Concepts on violence and socioeconomic data of people in extreme poverty, living in a city in Southern Brazil}

\author{
Márcia Cançado Figueiredo* \\ Vinícius Kothe** \\ Melina de Oliveira Cesar ${ }^{* * *}$
}

Kátia Valença Correia Leandro da Silva ${ }^{* * * *}$

\section{Resumo}

Objetivo: este trabalho buscou sistematizar o conhecimento acerca da violência e dos indicadores socioeconômicos de moradores de um bairro do município de Viamão, RS, cadastrados na Estratégia Saúde da Família Augusta Meneguine. Métodos: o presente trabalho é um estudo transversal observacional analítico desenvolvido mediante aplicação de questionários sobre violência e indicadores socioeconômicos. Resultados: a idade média dos 110 indivíduos avaliados foi de 35,2 anos ( $d p \pm$ 6,24), sendo $75,5 \%$ do gênero feminino e $24,5 \%$ do gênero masculino. Do total de participantes, $42,2 \%$ não trabalhavam, e destes, 16,4\% nunca tiveram emprego. Dentre os indivíduos que trabalhavam, 23,9\% apresentavam renda entre $R \$ 380,00$ e $R \$ 760,00$, e $33,6 \%$ tinham emprego fixo há mais de dois anos. Observou-se que 50\% eram casados, 31,8\% não tinham filhos e $54,5 \%$ residiam com quatro ou mais pessoas na mesma casa. Quanto à escolaridade, 38,2\% apresentavam o $1^{\text {o }}$ grau incompleto, 32,7\% nunca haviam reprovado de ano e 40,9\% haviam reprovado duas vezes, pelo menos. Não frequentam a escola atualmente $83,6 \%$. Sus- tentaram ser verdadeira a ideia de que a violência está restrita a camadas menos favorecidas no Brasil 44,5\%. Quase $20 \%$ desconhecem a lei do desarmamento e acreditam que a arma de fogo faz-se necessária para impor respeito. Conclusão: por meio dos questionários, foi possível identificar um perfil carente da população estudada: desemprego, pobreza, baixa remuneração e escolaridade. Essa comunidade apresentou potenciais para desencadear situações de risco para a violência.

Palavras-chave: Violência. Pobreza. Educação.

Professora Associada IV Regente das disciplinas de Atendimento Odontológico para Pacientes com Necessidades Especiais e Bebê Clínica da Faculdade de Odontologia da Universidade Federal do Rio Grande do Sul (UFRGS), Porto Alegre, RS, Brasil.

** Graduando do curso de Odontologia da UFRGS, Porto Alegre, RS, Brasil.

*** Cirurgiã-dentista, graduada no curso de Odontologia pela UFRGS, Porto Alegre, RS, Brasil.

***** Professora Associada IV do Instituto de Biociências da UFRGS, Porto Alegre, RS, Brasil. 


\section{Introdução}

Os casos de violência formam um conjunto de agravos que vem atingindo um crescente número de pessoas, de todas as idades e sexos, sendo considerado um sério problema de saúde pública brasileira. Somados às doenças crônicas e degenerativas, os casos de violência configuram um novo perfil no quadro de problemas de saúde do Brasil e do mundo ${ }^{1}$.

Violência é definida como o uso intencional da força, do poder físico, ou, ainda, da ameaça contra si mesmo, contra outra pessoa, contra um grupo ou comunidade que cause ou tenha possibilidade de causar lesões, morte, danos psicológicos, transtornos de desenvolvimento ou privações ${ }^{2}$. A Organização Mundial da Saúde (OMS) salienta, também, a natureza dos atos violentos como físico, sexual, psíquico, de privação ou de descuido ${ }^{2}$.

Prejuízos na saúde física e mental das pessoas, tais como transtorno de estresse pós-traumático, depressão, tentativas de suicídio, abuso e dependência de substâncias, obesidade, cardiopatias, doenças pulmonares crônicas, síndrome do cólon irritável, síndrome da fadiga crônica, fibromialgia, entre outros, são investigados como tendo correlação com a violência doméstica ${ }^{3}$.

As experiências traumáticas precoces podem estar relacionadas à alta morbidade psiquiátrica e também podem ser consideradas como um fator de risco para a violência doméstica durante a vida adulta. Estudos epidemiológicos mostraram forte correlação entre a ocorrência de traumas na infância e morbidades psiquiátricas na vida adulta ${ }^{4}$. Nessas circunstâncias, frequentemente, quem sofre violência a entende como um meio aceitável na resolução de conflitos, tornando-se, quando adulto, agressor ou vítima.

Essa repetição entre gerações tem sido apontada como um dos fatores explicativos para o crescimento da violência ${ }^{5}$. Logo, o fato de crescer em ambientes familiares violentos está associado a graves problemas comportamentais na infância e na adolescência ${ }^{6,7}$.

Diante desse panorama, buscou-se sistematizar o conhecimento acerca da violência e dos indicadores socioeconômicos de moradores da Vila Augusta Meneguine, do município de Viamão, RS, cadastrados na Estratégia Saúde da Família (ESF).

\section{Métodos}

O presente trabalho é transversal observacional analítico. Foi realizado mediante aplicação de questionários sobre violência desenvolvidos pela OMS (Figura 1) e com base em dados socioeconômicos tradicionais, em uma população que vive em situação de pobreza no município de Viamão, RS.
Idade: Gênero: $[\mathrm{M}][\mathrm{F}]$

Julgue as afirmativas abaixo, e circule se você acha VERDADEIRO (V) ou FALSO (F) (caso não concorde com a afirmaçăo). Caso não saiba o que responder ou desconheça o assunto tratado. arque não sabe afirmar (NSA).

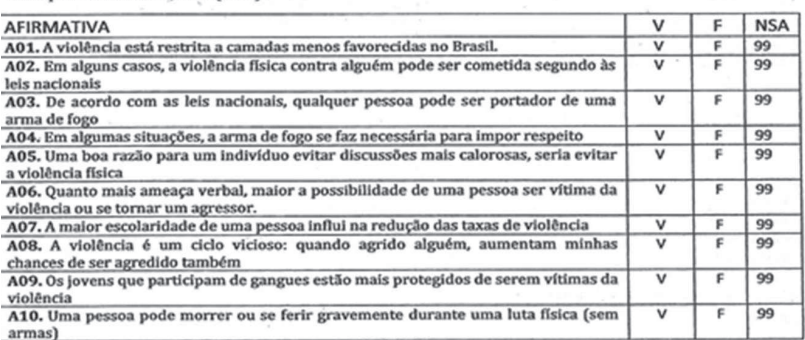

A10. Um

Gostaria que você me dissesse se DISCORDA TOTALMENTE (DT), DISCORDA (D), NEM SIM NEM NXT (NSNN), CONCORDA (CC) ou CONCORDA TOTALMENTE (CCT) com as frases abaixo, conforme OSAO (NSNM, CONCORDA (CC) ou CC

\begin{tabular}{|c|c|c|c|c|c|}
\hline AFIRMATIVA & DT & D & NSNN & cc & CCT \\
\hline $\begin{array}{l}\text { Bo1. B́ uma boa ideia nåo responder agressivamente a agressōes } \\
\text { verbals de outras pessoas. }\end{array}$ & DT & D & NSNN & CC & CCT \\
\hline $\begin{array}{l}\text { B02. As pessoas devem entender que andar armado, em } \\
\text { qualquer circunstancia, pode resultar em morte e ferimentos } \\
\text { desnecessários. }\end{array}$ & DT & D & NSNN & cc & CCT \\
\hline $\begin{array}{l}\text { B03. Náo há problema em andar armado de vez em quando. pols } \\
\text { orisco de utilizar a arma é muito pequeno. }\end{array}$ & DT & D & NSNN & CC & CCT \\
\hline $\begin{array}{l}\text { B04. Nào é uma boa ldeia acertar desavenças após ter } \\
\text { consumido álcool }\end{array}$ & DT & D & NSNN & cc & CतT \\
\hline $\begin{array}{l}\text { B05. Nao há problemas em dizer para uma pessoa conhecida: } \\
\text { vamos parar a discussto por aqui para năo brigarmos" }\end{array}$ & DT & D & NSNN & $\mathrm{CC}$ & $\mathrm{CCT}$ \\
\hline $\begin{array}{l}\text { B06. Nas há problema em usar violéncia fisica contra aqueles } \\
\text { que nos agridem verbalmente. }\end{array}$ & DT & D & NSNN & CC & CCT \\
\hline $\begin{array}{l}\text { B07. Pessoas que éa praticaram qualquer tipo de violencia contra } \\
\text { vocé ou um conhecido deviam morrer. }\end{array}$ & DT & D & NSNN & $\mathrm{CC}$ & CCT \\
\hline $\begin{array}{l}\text { Bo8. Em alguns casos, quando vocé é muito provocado por } \\
\text { alguém, isto quer dizer que esta pessoa quer apanhar. }\end{array}$ & DT & D & NSNN & $\mathrm{CC}$ & $\mathrm{CCT}$ \\
\hline $\begin{array}{l}\text { B09. Vocet teria vergonha se alguém te provocasse muito e voce } \\
\text { năo partisse para a briga na frente dos seus colegas e } \\
\text { conhecidos. }\end{array}$ & DT & D & NSNN & cC & $\mathrm{CCT}$ \\
\hline $\begin{array}{l}\text { B10. Em muitos casos, nåo há outra alternativa se năo partír } \\
\text { para a briga. }\end{array}$ & DT & 0 & NSNN & CC & CCT \\
\hline B11. Você se sentiria mais & DT & o & NSNN & $\mathrm{cC}$ & $\mathrm{CCT}$ \\
\hline $\begin{array}{l}\text { B12. Em alguns casos, o suicidio pode ser uma salda para os } \\
\text { problemas da vida. }\end{array}$ & OT & D & NSNN & & \\
\hline
\end{tabular}
problemas da vida.

Fonte: OMS, 2008.

Figura 1 - Questionário sobre violência desenvolvido pela Organização Mundial de Saúde, aplicado para 110 moradores do bairro Augusta Meneguine. Viamão, RS, 2012

As 110 pessoas que responderam aos questionários, usuárias da ESF da Unidade Básica de Saúde Augusta Meneguine, de Viamão, RS, eram maiores de 21 anos de idade e frequentavam pelo menos uma das atividades do Programa de Extensão Interdisciplinar de Educação em Saúde da Faculdade de Odontologia da UFRGS, realizadas aos sábados no referido estabelecimento (Figura 2). Os questionários eram aplicados em uma sala destinada para tal finalidade antes de cada pessoa receber o seu atendimento clínico multiprofissional.

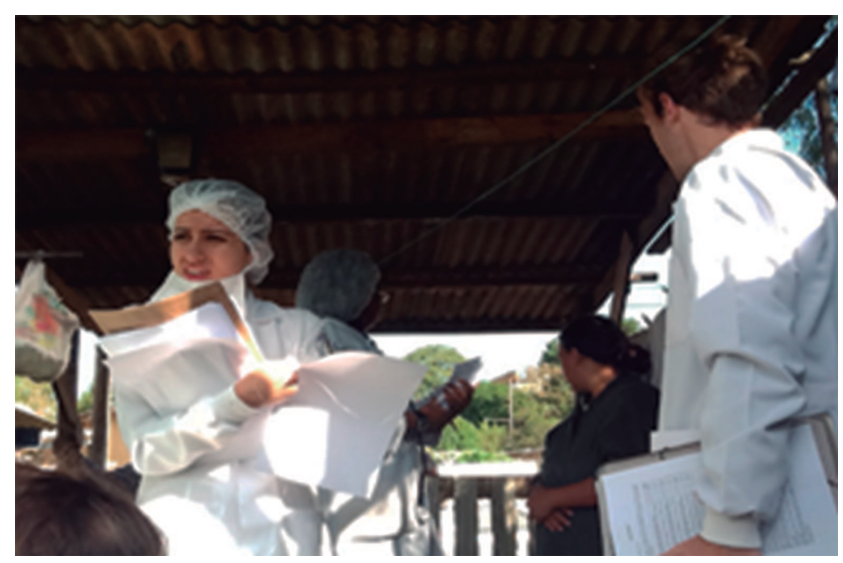

Figura 2 - Questionários sendo aplicados antes que cada pessoa participasse das atividades do Programa de Extensão Interdisciplinar de Educação em Saúde da Faculdade de Odontologia da UFRGS 
Os dados foram coletados e tabulados no programa Microsoft Excel ${ }^{\circledR}$ (Microsoft, USA, 2010), sendo analisados quantitativamente, com tabelamento em percentual, e apresentados em frequência relativa absoluta.

As variáveis analisadas foram as seguintes: idade, gênero, renda, tempo de trabalho, desemprego, estado civil, número de filhos, escolaridade, número de reprovações, referência pessoal, número de moradores na casa e questões sobre violência. Foram reportados dados descritivos dessas variáveis, sendo as quantitativas expressas pela distribuição de frequências, excetuando a idade, que foi avaliada por meio de média e desvio padrão.

$\mathrm{O}$ projeto desta pesquisa foi aprovado pelo Comitê de Ética em Pesquisa da Secretaria Municipal de Saúde da Prefeitura Municipal de Porto Alegre (CEP nํ6ㅇ).

\section{Resultados}

A idade média dos 110 indivíduos avaliados foi de 35,2 anos (dp $\pm 16,2$ ), sendo 75,5\% do gênero feminino e $24,5 \%$ do gênero masculino.

Nos dados socioeconômicos, notou-se que $42,2 \%$ das pessoas não trabalhavam, e destas, $16,4 \%$ nunca tiveram emprego. Dentre os indivíduos que trabalhavam, 23,9\% apresentavam renda entre $R \$$ 380,00 e $\mathrm{R} \$ 760,00$, e $33,6 \%$ tiveram emprego fixo há mais de dois anos, conforme ilustrado na Tabela 1.

Tabela 1 - Distribuição dos indivíduos quanto ao desemprego, à renda, ao tempo que o indivíduo estava trabalhando e ao tempo que estava desempregado, em percentual. Viamão, RS, 2012

\begin{tabular}{l|c}
\multicolumn{1}{c|}{$\begin{array}{c}\text { Distribuição dos indivíduos quanto ao } \\
\text { desemprego e à renda }\end{array}$} & $\%$ \\
\hline Não trabalha & 42,2 \\
Menos de R\$ 380,00 & 1,8 \\
R\$ 380,00 & 1,8 \\
R\$ 380,01 a R\$ 760,00 & 23,9 \\
R\$ 760,01 a R\$ 1140,00 & 19,3 \\
R\$ 1140,01 a R\$ 1520,00 & 8,3 \\
R\$ 1520,01 a R\$ 1900,00 & 2,8 \\
Acima de R\$ 1900,01 & 0 \\
\hline Tempo que o indivíduo está trabalhando & 8,2 \\
\hline Menos de 1 ano & 14,5 \\
De 1 a 2 anos & 33,6 \\
Mais de 2 anos & \\
\hline Tempo que o indivíduo está sem emprego & 16,4 \\
\hline Nunca trabalhou & 7,3 \\
Menos de 1 ano & 5,5 \\
De 1 a 2 anos & 14,5 \\
Mais de 2 anos &
\end{tabular}

Observou-se que 50\% eram casados, $31,8 \%$ não tinham filhos e 54,5\% residiam com quatro ou mais pessoas na mesma casa. A "mãe" foi considerada a principal referência pessoal por $50 \%$ dos indivíduos (Tabela 2).
Tabela 2 - Distribuição dos indivíduos quanto ao estado civil, ao número de filhos, ao número de moradores da casa e à principal referência pessoal, em percentual. Viamão, RS, 2012

\begin{tabular}{l|c}
\hline Estado civil & $\%$ \\
\hline Solteiro & 40,9 \\
Casado & 50 \\
Separado & 5,5 \\
Outros & 3,6 \\
\hline Número de filhos & 31,8 \\
\hline 0 & 34,5 \\
1 a 2 & 33,6 \\
3 ou mais & \\
\hline Número de moradores da casa & 45,5 \\
\hline 1 a 3 & 54,5 \\
4 ou mais & 24,5 \\
\hline Principal referência pessoal & 50 \\
\hline Pai & 8,2 \\
Mãe & 17,2 \\
Irmão & \\
Outros &
\end{tabular}

As Figuras 3, 4 e 5 ilustram o grau de escolaridade da população estudada, a sua distribuição na escola, bem como o número de reprovações que obtiveram.

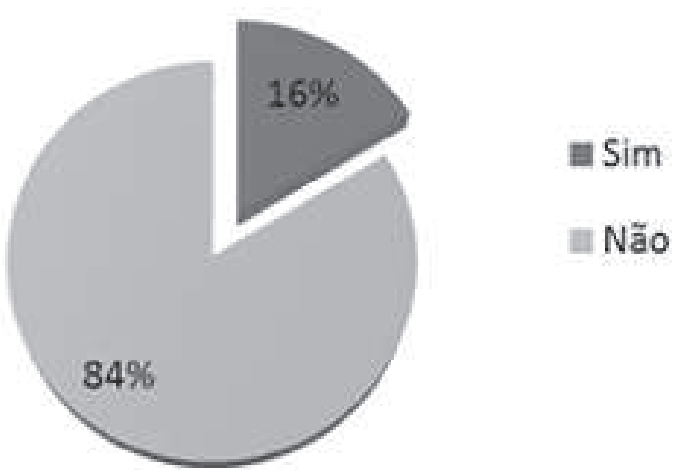

Figura 3 - Distribuição dos indivíduos que frequentavam alguma instituição de ensino. Viamão, RS, 2012

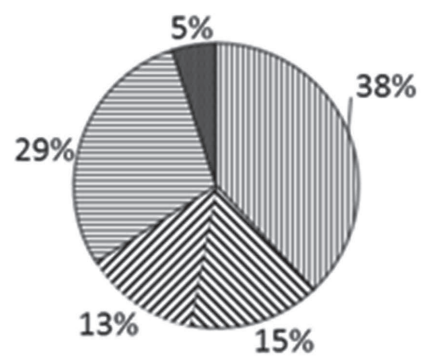

四1ㅇg grau incompleto

$\$ 10$ grau completo

Z 20 grau incompleto

目 20 grau completo

outros

Figura 4 - Distribuição do grau de escolaridade. Viamão, RS 


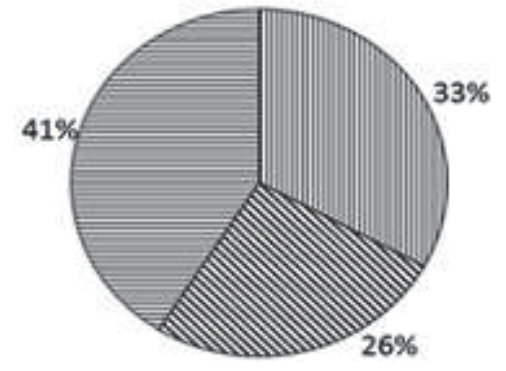

\section{四zero}

Suma

Gduas ou mais

Figura 5 - Distribuição do número de reprovações. Viamão, RS

Questionando-se a população sobre o tema violência, 53,6 \% disseram ser falsa e 44,5\% responderam ser verdadeira a afirmativa de que violência está restrita a camadas menos favorecidas no Brasil. Com relação à afirmação "Em alguns casos, a violência física contra alguém pode ser cometida segundo as leis nacionais", $56,4 \%$ disseram ser falsa e $38,2 \%$, verdadeira. Já no que se refere à alternativa "De acordo com as leis nacionais, qualquer pessoa pode ser portadora de uma arma de fogo", $82,7 \%$ responderam ser falsa e $14,5 \%$ ser verdadei- ra. Quanto à assertiva "Em algumas situações, a arma de fogo se faz necessária para impor respeito", $74,5 \%$ disseram ser falsa e $20 \%$ disseram ser verdadeira. No caso da afirmação "Uma boa razão para um indivíduo evitar discussões mais calorosas seria evitar a violência física", 94,5\% responderam ser verdadeira e 4,5\%, ser falsa. Quando indagados em relação à assertiva "Quanto mais ameaça verbal, maior a possibilidade de uma pessoa ser vítima da violência ou se tornar um agressor", 94,5\% consideraram ser verdadeira e $3,6 \%$, falsa. No momento em que foram questionados se a maior escolaridade de uma pessoa influi na redução das taxas de violência, 55,5\% disseram ser verdadeira e $42,7 \%$ responderam ser falsa a afirmativa. Já na alternativa "A violência é um círculo vicioso: quando agrido alguém, aumentam minhas chances de ser agredido também", 93,6\% disseram ser verdadeiro e 3,6\%, ser falsa. À assertiva "Os jovens que participam de gangues estão mais protegidos de serem vítimas da violência", 79,1\% responderam ser falsa e $18,2 \%$, ser verdadeira. Por fim, diante da afimação "Uma pessoa pode morrer ou se ferir gravemente durante uma luta física (sem armas)", 95,5\% disseram ser verdadeira e $3,6 \%$, ser falsa (Tabela 3 ).

Tabela 3 - Distribuição das respostas referentes às perguntas sobre violência, em percentual. Viamão, RS, 2012.

\begin{tabular}{|c|c|c|c|}
\hline Afirmativas & Verdadeiro (\%) & Falso $(\%)$ & Não sabe (\%) \\
\hline A violência está restrita a camadas menos favorecidas no Brasil. & 44,5 & 53,6 & 1,8 \\
\hline $\begin{array}{l}\text { Em alguns casos, a violência física contra alguém pode ser cometida segundo as } \\
\text { leis nacionais. }\end{array}$ & 38,2 & 56,4 & 5,4 \\
\hline $\begin{array}{l}\text { De acordo com as leis nacionais, qualquer pessoa pode ser portadora de uma } \\
\text { arma de fogo. }\end{array}$ & 14,5 & 82,7 & 2,7 \\
\hline Em algumas situações, a arma de fogo se faz necessária para impor respeito. & 20 & 74,5 & 5,5 \\
\hline $\begin{array}{l}\text { Uma boa razão para um indivíduo evitar discussões mais calorosas seria evitar a } \\
\text { violência física. }\end{array}$ & 94,5 & 4,5 & 0,9 \\
\hline $\begin{array}{l}\text { Quanto mais ameaça verbal, maior a possibilidade de uma pessoa ser vítima da } \\
\text { violência ou se tornar um agressor. }\end{array}$ & 94,5 & 3,6 & 1,8 \\
\hline A maior escolaridade de uma pessoa influi na redução das taxas de violência. & 55,5 & 42,7 & 1,8 \\
\hline $\begin{array}{l}\text { A violência é um círculo vicioso: quando agrido alguém, aumentam minhas } \\
\text { chances de ser agredido também. }\end{array}$ & 93,6 & 3,6 & 2,7 \\
\hline $\begin{array}{l}\text { Os jovens que participam de gangues estão mais protegidos de serem vítimas da } \\
\text { violência. }\end{array}$ & 18,2 & 79,1 & 2,7 \\
\hline $\begin{array}{l}\text { Uma pessoa pode morrer ou se ferir gravemente durante uma luta física (sem } \\
\text { armas). }\end{array}$ & 95,5 & 3,6 & 0,9 \\
\hline
\end{tabular}

Quanto aos resultados de um segundo questionário sobre violência, os participantes tiveram mais opções de resposta: 60,0\% concordaram totalmente com a afirmativa de que "é uma boa ideia não responder agressivamente a agressões verbais de outras pessoas", enquanto 4,5\% discordaram. Diante da sentença "As pessoas devem entender que andar armado, em qualquer circunstância, pode resultar em morte e ferimentos desnecessários", 66,4\% concordaram totalmente e $0,9 \%$ não responderam. Em relação à assertiva "Não há problema em andar armado de vez em quando, pois o risco de utilizar a arma é muito pequeno", $63,6 \%$ discordaram to- talmente e 4,5\% concordaram totalmente. Em seguida, foram indagados sobre a afirmativa "Não é uma boa ideia acertar desavenças após ter consumido álcool”, sobre a qual $62,7 \%$ responderam que concordavam totalmente e $4,5 \%$ nem concordaram, nem discordaram. Na questão "Não há problemas em dizer para uma pessoa conhecida: vamos parar a discussão por aqui para não brigarmos", 70,0\% concordaram totalmente e 0,9\% discordaram. Já em relação à afirmativa "Não há problema em usar violência física contra aqueles que nos agridem verbalmente", $60,0 \%$ discordaram totalmente e 7,3\% responderam nem sim nem não. Ao lerem a frase 
"Pessoas que já praticaram qualquer tipo de violência contra você ou um conhecido deviam morrer", $73,6 \%$ discordaram totalmente e 1,8\% concordaram. Questionados sobre a assertiva "Em alguns casos, quando você é muito provocado por alguém, isso quer dizer que essa pessoa quer apanhar", $46,4 \%$ discordaram totalmente e $6,4 \%$ concordaram. Na afirmativa "Você teria vergonha se alguém te provocasse muito e você não partisse para a briga na frente dos seus colegas e conhecidos", $54,5 \%$ discordaram totalmente. Dentre os entrevistados, $55,5 \%$ discordaram totalmente e 5,5\% responderam nem sim nem não em relação à seguinte sentença: "Em muitos casos, não há outra alternativa se não partir para a briga". No que se refere à assertiva "Você se sentiria mais seguro participando de uma gangue", 77,3\% discordaram totalmente e $0,9 \%$ concordaram. Por fim, 76,4\% discordaram totalmente da afirmativa "Em alguns casos, o suicídio pode ser uma saída para os problemas da vida" (Tabela 4).

Tabela 4 - Distribuição das respostas referentes às perguntas sobre violência, em percentual. Viamão, RS, 2012

\begin{tabular}{|c|c|c|c|c|c|}
\hline Afirmativas & $\begin{array}{l}\text { Discorda } \\
\text { totalmente }\end{array}$ & Discorda & $\begin{array}{l}\text { Nem sim } \\
\text { nem não }\end{array}$ & Concorda & $\begin{array}{l}\text { Concorda } \\
\text { totalmente }\end{array}$ \\
\hline $\begin{array}{l}\text { É uma boa ideia não responder agressivamente a } \\
\text { agressões verbais de outras pessoas. }\end{array}$ & 10,0 & 4,5 & 9,1 & 16,4 & 60,0 \\
\hline $\begin{array}{l}\text { As pessoas devem entender que andar armado, } \\
\text { em qualquer circunstância, pode resultar em } \\
\text { morte e ferimentos desnecessários. }\end{array}$ & 5,5 & 3,6 & 0,9 & 23,6 & 66,4 \\
\hline $\begin{array}{l}\text { Não há problema em andar armado de vez em } \\
\text { quando, pois o risco de utilizar a arma é muito } \\
\text { pequeno. }\end{array}$ & 63,6 & 19,1 & 6,4 & 6,4 & 4,5 \\
\hline $\begin{array}{l}\text { Não é uma boa ideia acertar desavenças após ter } \\
\text { consumido álcool. }\end{array}$ & 8,2 & 5,5 & 4,5 & 19,1 & 62,7 \\
\hline $\begin{array}{l}\text { Não há problemas em dizer para uma pessoa co- } \\
\text { nhecida: "vamos parar a discussão por aqui para } \\
\text { não brigarmos". }\end{array}$ & 3,6 & 0,9 & 1,8 & 23,6 & 70,0 \\
\hline $\begin{array}{l}\text { Não há problema em usar violência física contra } \\
\text { aqueles que nos agridem verbalmente. }\end{array}$ & 60,0 & 15,5 & 7,3 & 9,1 & 8,2 \\
\hline $\begin{array}{l}\text { Pessoas que já praticaram qualquer tipo de vio- } \\
\text { lência contra você ou um conhecido deviam } \\
\text { morrer. }\end{array}$ & 73,6 & 19,1 & 3,6 & 1,8 & 1,8 \\
\hline $\begin{array}{l}\text { Em alguns casos, quando você é muito provoca- } \\
\text { do por alguém, isso quer dizer que essa pessoa } \\
\text { quer apanhar. }\end{array}$ & 46,4 & 25,5 & 10,0 & 6,4 & 11,8 \\
\hline $\begin{array}{l}\text { Você teria vergonha se alguém te provocasse mui- } \\
\text { to e você não partisse para a briga na frente dos } \\
\text { seus colegas e conhecidos. }\end{array}$ & 54,5 & 15,5 & 10,0 & 10,0 & 10,0 \\
\hline $\begin{array}{l}\text { Em muitos casos, não há outra alternativa se não } \\
\text { partir para a briga. }\end{array}$ & 55,5 & 22,7 & 5,5 & 9,1 & 7,3 \\
\hline $\begin{array}{l}\text { Você se sentiria mais seguro participando de uma } \\
\text { gangue. }\end{array}$ & 77,3 & 13,6 & 6,4 & 0,9 & 1,8 \\
\hline $\begin{array}{l}\text { Em alguns casos, o suicídio pode ser uma saída } \\
\text { para os problemas da vida. }\end{array}$ & 76,4 & 10,9 & 7,3 & 2,7 & 2,7 \\
\hline
\end{tabular}

\section{Discussão}

Trabalhou-se em uma comunidade que vivia em condições precárias, uma vez que a maioria das famílias tinha uma renda mensal inferior a um salário mínimo, tendo quatro ou mais moradores por casa, ou seja, um grande número de pessoas concentradas por domicílio. Segundo Cardia e Schiffer ${ }^{8}$ (2002), os espaços domésticos podem ter usos múltiplos: salas de estar podem ser usadas como dormitórios, cozinhas podem servir como áreas de estudo, e assim por diante. Isso concorre para o estresse familiar, quando atividades nem sempre compatíveis precisam ser realizadas simultaneamente. Além do desconforto psicológico, há o risco de prejuízo para crianças que precisam se concentrar para estudar e a falta de privacidade para os adultos, o que também pode facilitar o conflito interpessoal.

A situação de desemprego foi superior a $40 \%$ na população estudada, a qual apresentou uma média de idade de 35 anos. Crê-se que uma taxa elevada e constante de desemprego que se mantenha durante muito tempo tenderá a levar as pessoas - principalmente adultos jovens - para o mundo do crime. Estudos sobre população prisional indicaram proporções elevadas de delinquentes procedentes do mercado informal que jamais tiveram carteira profissional assinada ou contrato formal de trabalho 
firmado $^{9-11}$. O estudo de Crutchfield e Pitchford ${ }^{12}$, em 1997, demonstrou uma relação entre emprego e desemprego e a prática de crimes violentos e contra propriedades.

Além disso, o grau de escolaridade encontrado foi muito baixo, considerando-se que quase $40 \%$ tinham apenas o primeiro grau incompleto e com mais de $60 \%$ de reprovações escolares (Figuras 4 e 5). Soares et al. ${ }^{13}$, em 2007, ressaltaram que os jovens com baixa escolaridade são, também, o agrupamento onde mais se concentram as taxas de vitimização por homicídio no Brasil, uma curva que, entretanto, cai muito acentuadamente para aqueles que terminam o ensino fundamental ${ }^{13,14}$. Uma pesquisa realizada em um presídio de Brasília constatou que três em cada quatro presos não terminaram o primeiro grau e que apenas $7 \%$ deles haviam alcançado o nível médio ou mais ${ }^{14}$. Destaca-se, ainda, que o incentivo ao engajamento nas atividades da escola, da comunidade e de movimentos sociais ou de solidariedade mostra-se um potente fator protetor à violência ${ }^{15}$; ou seja, uma ação preventiva concentrada em áreas como a deste estudo e focada nos grupos mais desfavorecidos - adultos jovens do sexo masculino que abandonaram a escola ou que nunca estudaram, desempregados ou subempregados - deverá contribuir para uma desaceleração brusca dos índices de violência.

Ademais, tratou-se de uma população jovem, sendo mais da metade casados e com mais de três filhos (Tabela 2). O viver ali passou a ser limitado à sobrevivência, e os problemas relacionados à violência tenderiam a aparecer, porque, sem dúvida alguma, a insuficiência de segurança nas moradias seria um elemento central para explicar o surgimento de gangues e outros grupos armados nessas localidades. Além disso, o estudo de Muszkat ${ }^{16}$, em 2002, comprovou que o ciclo da violência começa cedo na vida das pessoas - começa quando crianças; são os filhos de famílias violentas, de mulheres violentadas que se sentem abandonados e não encontram, no seu ambiente, razões para crer que são importantes, quando são diretamente abusados ou quando aprendem, observando as relações entre os adultos, que a violência é um meio aceitável na resolução dos problemas.

Neste estudo, para a maior parte dos entrevistados, as mulheres foram as pessoas mais citadas como referência de vida pessoal. A literatura tem demonstrado que a violência atinge mulheres de todas as faixas etárias, com um predomínio de vítimas jovens, sendo a maioria das agressões praticada no interior da residência, pelo fato de não haver interrupções de outras pessoas, sob a privacidade do lar. $\mathrm{O}$ ambiente doméstico propicia que familiares ou pessoas conhecidas e de confiança da mulher sejam os agressores, facilitando o ato e dificultando sua identificação ${ }^{17}$.
Esses resultados quantitativos demonstram que essa população teria poucas oportunidades para superar sua condição econômica e social de desvantagem, fato que, possivelmente, levou quase metade das pessoas a responder ser verdadeira a afirmação de que a violência está restrita a camadas menos favorecidas. Dias ${ }^{18,}$ em 1998, afirmou serem as famílias em situações de exclusão social mais vulneráveis à violência doméstica: condições de habitação deficitárias, condições de saúde precárias, baixos níveis de escolaridade, existência de desemprego e de precariedade face ao trabalho, baixos níveis de rendimentos e de qualificação profisssional, incidência da economia informal, maior segregação espacial e consequente isolamento social, frequência de famílias de grande dimensão com elevada natalidade e de famílias monoparentais, incidência de comportamentos aditivos, elevadas taxas de criminalidade e de marginalidade no contexto social envolvente etc. Cano ${ }^{19}$, em 1996, e Szwarcwald et al. ${ }^{20}$, em 1999, demonstraram, também, que há maior concentração de homicídios nas áreas de pobreza do Rio de Janeiro, assim como Beato et al. ${ }^{21}$, em 2001, referindo-se a Belo Horizonte e Santos et al. ${ }^{22}$, no mesmo ano, falando de Porto Alegre. Segundo Massey ${ }^{23}$, à medida que a pobreza aumenta em um determinado local, ali crescerão a criminalidade, a mortalidade infantil, o abuso de drogas, o alcoolismo e doenças de uma forma geral.

Além disso, quase $20 \%$ dos entrevistados desconheciam a Lei $\mathrm{n}^{\mathrm{o}} 10.82624$, de 22 de dezembro de 2003, que estabeleceu a proibição do porte de arma de fogo em todo o território nacional, salvo em casos excepcionais. Segundo Kahn ${ }^{25}$ (2002), os proprietários de armas ilegais são, principalmente, os de baixa escolaridade, ao contrário do que ocorre entre os proprietários de armas legais. Neste estudo, quase $40 \%$ dos entrevistados tinham apenas o primeiro grau incompleto, e a metade desse percentual acreditava no respeito dado por uma arma de fogo, reforçando ainda mais o risco de violência no local.

Na mesma linha da preocupação anterior, outro percentual expressivo das respostas dos entrevistados foi quanto a ser uma boa ideia acertar desavenças após ter consumido álcool. Segundo Minayo ${ }^{26}$, o abuso do álcool e de outras substâncias é um fator fundamental associado aos homicídios, à violência no trânsito ${ }^{27}$, à violência interpessoal e doméstica ${ }^{28}$ e à violência em geral ${ }^{29}$. Crê-se que o álcool deva rebaixar a crítica do indivíduo e potencializar a sua agressividade. A embriaguez dos maridos e/ou companheiros é um fator determinante nas situações de violência contra as mulheres, e esta, por sua vez, perdura por anos a fio numa família sem que a vítima e/ou o agressor procure(m) ajuda. O medo e a vergonha são os maiores obstáculos para o não enfrentamento da questão $0^{30}$. 
O tema "gangue", como sinônimo de demonstração de agressividade, vandalismo e selvageria, também foi abordado porque estudos têm demonstrado que, quando as pessoas entram para as gangues, tornam-se mais violentas e começam a participar de atividades ilegais e de maior risco ${ }^{31}$. Neste estudo, 1/5 dos entrevistados acreditou que participar de uma gangue seria um fator protetor à vitimização da violência. Acredita-se que esse resultado tenha ocorrido em razão da ausência de segurança pública efetiva no município, levando a que essa população reconstruísse microssociedades e microculturas onde a "grande" sociedade havia fracassado.

Todas as respostas dos entrevistados requerem muita reflexão e urgentes respostas, uma vez que comportamentos sociais inadequados continuam a ameaçar gravemente a sociedade, e isso é simplesmente inaceitável. Desse modo, o tema violência deverá ser uma prioridade das políticas públicas do município de Viamão, RS, uma vez que, em meio a tantos problemas, os moradores do Bairro Augusta Meneguini puderam, ainda, demonstrar uma pequena noção de como devem se proteger da violência, ao responderem negativamente às questões: "Pessoas que já praticaram qualquer tipo de violência contra você ou um conhecido deviam morrer" e "Você se sentiria mais seguro participando de uma gangue".

Violência é um tema que deve ser trabalhado interdisciplinarmente. O Ministério da Saúde $^{32}$ (2008) propõe capacitar e mobilizar os profissionais de saúde que atuam em todos os níveis de atendimento do SUS, inclusive nas unidades de urgência e emergência, com vistas a superar os problemas relacionados à investigação e à informação relativa a acidentes e violências. Também propõe estimular a característica interdisciplinar e a cooperação entre diferentes campos do conhecimento e centros de ensino e pesquisa para poder enfrentar a complexidade de um tema multifacetado. Os profissionais da saúde, principalmente aqueles que mantêm contato direto com os pacientes, são capazes de observar, analisar, diagnosticar os sinais da violência, muitas vezes estampados no seu semblante. Devemos estar atentos não somente às tarefas do cotidiano, mas também a esses sinais sutis que muitas vezes escondem grande sofrimento.

\section{Conclusão}

Por meio dos questionários, foi possível identificar um perfil carente da população estudada: desemprego, pobreza, baixa remuneração e escolaridade, apresentando potenciais para desencadear situações de risco para a violência.

\section{Agradecimentos}

Agradecemos à Dra. Virginia Espina, coordenadora de Saúde Bucal da Secretaria Municipal de Saúde do município de Viamão, pelas informações cedidas e por facilitar o trabalho realizado junto à Vila Augusta.

Financiamento: Ministério da Educação/SESu/ Edital PROEXT

\section{Abstract}

Objective: this study aimed to describe the knowledge of violence and socioeconomic indicators of residents from the city of Viamão, RS registered in the Health Strategy of the Augusta Meneguine family. Methodology: this is an observational cross-sectional and analytical study based on the application of questionnaires about violence and socioeconomic indicators. Results: the mean age of the 110 individuals evaluated was 35.2 years old (sd \pm 16.24$)$, with $75.5 \%$ female and $24.5 \%$ male. $42.2 \%$ of people did not work, and $16.4 \%$ had never had a job. Among the individuals who worked, $23.9 \%$ had income between $R \$ 380.00$ to $R \$ 760.00$, and $33.6 \%$ had a steady job for more than two years. It was observed that $50 \%$ of individuals were married, $31.8 \%$ had no children and lived with four people or more in the same household (54.5\%). Regarding education, $38.2 \%$ of individuals had not completed basic education, $32.7 \%$ had never failed a class, and $40.9 \%$ had failed at least twice. $83.6 \%$ of individuals currently do not attend school. $44.5 \%$ affirm the idea that in Brazil violence is restricted to the less favored. Nearly $20 \%$ of individuals do not know the disarmament law and believe that firearms are necessary to enforce compliance. Conclusion: through the questionnaires it was possible to identify the profile of a deprived population: unemployment, poverty, low income, and poor education. This community had the potential to trigger risk situations for violence.

Keywords: Violence. Poverty. Education.

\section{Referências}

1. Minayo MCS. Violência e saúde. Rio de Janeiro: Fiocruz; 2006. (Coleção Temas em Saúde).

2. Organização Mundial da Saúde. Guidelines for medico-legal care for victims of sexual violence. Genebra: WHO; 2003.

3. Silva MA. Prevalência e fatores associados à violência doméstica contra as mulheres assistidas no Centro de Atenção à Mulher [Dissertação de Mestrado]. Recife: Instituto Materno Infantil Professor Fernando Figueira; 2006.

4. Draibe SM. Por um reforço de proteção à família: contribuição à reforma dos programas de assistência social no Brasil. In: Kaloustian SN. Família brasileira, a base de tudo. 7. ed. São Paulo: Cortez; Brasília: Unicef; 1994. p. 109-30.

5. Klevens J. Violencia física contra la mujer en Santa Fé de Bogotá: Prevalência y factores asociados. Rev Panam Salud Publica 2001; 9(2):78-83. 
6. Pagani LS, Japel C, Vaillancourt T, Tremblay RE. Links between middle-Childhood trajectories of family dysfunction and indirect aggression. J Interpers Violence 2010; 20(10):124.

7. Knutson JF, Lawrence E, Taber SM, Bank L, DeGarmo DFS. Assessing children's exposure to intimate partner violence. Clin Child Fam Psychol Rev 2009; 12(2):157-73.

8. Cardia N, Schiffer, S. Violência e desigualdade social. Cien Cult 2002; 54(1):25-31.

9. Brant VC. O trabalho encarcerado. Rio de Janeiro: Forense; 1994.

10. Adorno S, Bordini E. Reincidência e reincidentes penitenciários em São Paulo, 1974-1985. Rev Bras Ci Soc 1989; 9(3):7094.

11. Adorno S. Exclusão socioeconômica e violência urbana. Sociologias 2002; 8: 84-135.

12. Chutchfield RD, Pitchford SR. Work and crime: the effects of labor stratification. Social Forces 1997; 76(1):93-118.

13. Soares AM, Souza, MF, Carvalho CZ, Malta DC, Alencar AP, Silva MA, et al. Análise da mortalidade por homicídios no Brasil. Epidemiol Serv Saúde 2007; 16(1):7-18.

14. Rolim M. Mais educação, menos violência: caminhos inovadores do programa de abertura das escolas públicas nos fins de semana. Brasília: Unesco, Fundação Vale; 2008.

15. Schenker M, Minayo MC. Risk and protective factors and drug use among adolescence. Ciênc Saúde Colet 2005; 10(2):707-17.

16. Muszkat M. Violência e intervenção. In: Correia M. Gênero e cidadania. Campinas: Unicamp; 2002. (Encontros. Pagu/ Núcleo de Estudos de Gênero).

17. Lopez IMRS, Gomes KRO, Silva BB, Deus MCBR, Galvão ERCGN, Borba DV. Caracterização da violência sexual em mulheres atendidas no Projeto Maria-Maria em Teresina, PI. Rev Bras Ginecol Obstet 2004; 26(2):111-6.

18. Dias I. Exclusão social e violência doméstica: que relação? [online] 1998 [citado 2012 Out 14]. Disponível em URL: http://ler.letras.up.pt/uploads/ficheiros/1457.pdf.

19. Cano I. Análise territorial da violência no Rio de Janeiro. CEDEC. Mapa de Risco da Violência: Cidade de São Paulo. São Paulo: editora; 1996.

20. Szwarcwald CL, Bastos FI, Esteves MA, Andrade CL, Paez MS, Medici EV, et al. Desigualdade de renda e situação de saúde: o caso do Rio de Janeiro. Cad Saúde Pública 1999; 15(1):15-28.

21. Beato CCF, Assunção RM, Almeida MCM. Conglomerados de homicídios e o tráfico de drogas em Belo Horizonte, Minas Gerais, Brasil de 1995 a 1999. Cad de Saúde Pública 2001; 17(5):1163-71.

22. Santos SM, Barcellos C, Carvalho MS, Flôres R. Detecção de aglomerados espaciais de óbitos por causas violentas em Porto Alegre, Rio Grande do Sul. Cad de Saúde Pública, 2001; 17(5):1141-51.

23. Massey D. The age of extremes: concentrated affluence and poverty in the twenty-first century. Demography 1996; 33(4):395-412.
24. Brasil. Lei no 10.826 , de 22 de dezembro de 2003. Dispõe sobre registro, posse e comercialização de armas de fogo e munição, sobre o Sistema Nacional de Armas [online] 2003 [citado 2012 Out 10]. Disponível em URL: http://www.planalto.gov.br/ccivil_03/leis/2003/L10.826.htm.

25. Kahn, T. Armas de fogo: argumentos para debate. Boletim Conjuntura Criminal, 2002. [Internet]. [citado 2012 out 15]. Disponível em URL: http://comunidadesegura.org.br/files/ armasdefogotuliokahn.pdf.

26. Minayo MCS, Assis SG. Violência e saúde na infância e adolescência: uma agenda de investigação estratégica. Divulg Saúde Debate 1993; 17(39):58-63.

27. Got C. Una libertad demasiado cara. Salud Mundial 1993; 46(1):71.

28. Deslandes S F. Prevenir e proteger: análise de um serviço de atenção aos maus tratos na infância [Dissertação de Mestrado]. Rio de Janeiro: Escola Nacional de Saúde Pública; 1993.

29. Fagan J. Interactions among drugs, alcohol and violence. Health Aff 1993; 12(4):65-79.

30. Assis SG. Quando crescer é um desafio social: estudo sócioepidemiológico sobre violência em escolares em Duque de Caxias [Dissertação de Mestrado]. Rio de Janeiro: Escola Nacional de Saúde Pública; 1991.

31. Organização Mundial da Saúde. Violência - um problema mundial de saúde pública. In: Relatório mundial sobre violência e saúde. Genebra: OMS; 2002.

32. Brasil. Ministério da Saúde. Propostas, estratégias e parcerias por área de atuação. In: O desafio do enfrentamento da violência: situação atual, estratégias e propostas. Brasília: Ministério da Saúde, 2008.

\section{Endereço para correspondência:}

Márcia Cançado Figueiredo Faculdade de Odontologia da UFRGS

Rua Ramiro Barcelos, 2492

90035-003 - Porto Alegre/RS

Fones: (51) 3308 5027/5026

E-mail:mcf1958@gmail.com

Recebido: 26/03/2013. Aceito: 28/06/2013. 